\title{
INFRA-ESTRUTURAS VERDES PARA UM FUTURO URBANO SUSTENTÁVEL. O CONTRIBUTO DA ESTRUTURA ECOLÓGICA E DOS CORREDORES VERDES.
}

\author{
José Carlos Ferreira \\ Mestre, Doutorando em Eng ${ }^{\text {a }}$ do Ambiente e Assistente do \\ Dep. Ciências e Engenharia do Ambiente, Faculdade de Ciências e Tecnologia, Universidade Nova \\ de Lisboa- Campus da Caparica 2829-516 Caparica Portugal, jcrf@fct.unl.pt \\ Pesquisador no CENSE - Centre for Environmental and Sustainability Research / UNL. \\ João Reis Machado \\ Professor Doutor, Professor com Agregação do \\ Dep. Ciências e Engenharia do Ambiente, Faculdade de Ciências e Tecnologia, Universidade Nova \\ de Lisboa- Campus da Caparica 2829-516 Caparica Portugal, jmachado@fct.unl.pt
}

\section{RESUMO}

A "infra-estrutura verde" é definida por uma rede de áreas naturais e áreas abertas (open spaces) fundamentais para o funcionamento ecológico do território, contribuindo para a preservação dos ecossistemas naturais, da vida selvagem, para a qualidade do ar e da água e para a qualidade de vida dos cidadãos. Para Bennedict e McMahon (2006), Uma infra-estrutura verde consiste numa rede ecológica que engloba as componentes ambientais, sociais e económicas, ou seja, uma rede para o suporte da vida.

Em Portugal, a infra-estrutura verde é designada por Estrutura Ecológica da paisagem ou do território. De acordo com Ferreira (2010a), esta estrutura reconhece os sistemas ecológicos fundamentais e orientadores de uma implementação sustentável da estrutura edificada de forma a promover a biodiversidade em ambiente urbano. $\mathrm{O}$ mesmo autor refere ainda que a definição de uma Rede de Corredores Verdes com base na Estrutura Ecológica proporciona um instrumento eficaz de requalificação ambiental de territórios desestruturados, com especial ênfase nas áreas urbanas, constituindo igualmente uma excelente base para a definição de uma Estrutura Ecológica Urbana.

O presente artigo discute o contributo das Infraestruras-verdes, das Estruturas Ecológicas e das Rede de Corredores Verdes para a definição de um modelo de ocupação urbana sustentável em áreas sob pressão urbana.

Palavras-chave: Infra-estrutura verde, corredores verdes, estrutura ecológica e urbanismo sustentável. 


\title{
GREEN INFRASTRUCTURES FOR A SUSTAINABLE URBAN FUTURE. THE ECOLOGICAL STRUCTURE AND THE GREENWAYS' CONTRIBUTIONS
}

\begin{abstract}
The "Green infrastructures" are defined by a network of natural areas and open spaces considered fundamental for the ecological functioning of the territory, contributing for the preservation of the natural ecosystems, for the wildlife, for the quality of the air and water as well as for the citizens quality of life. For Bennedict and McMahon (2006), a green infrastructure consists in an ecological network that includes the environmental, social and economical components, meaning a network for the support of life.

In Portugal the green infrastructure is defined as ecological structure of the landscape or territory. According to Ferreira (2010a), such a structure recognizes the ecological systems as fundamentals and guiding elements for a sustainable implementation of the built structures, as a way to promote the biodiversity on a urban environment. The same author also refers that the definition of a greenways network, based on ecological structure is an efficient tool in the environmental requalification of unstructured territories, particularly the urban areas, allowing also an excellent basis for the definition of an urban ecological structure.

The present report discusses the green substructures, the ecological structures and the greenways networks' contribution for the definition of a sustainable urban occupation in areas under urban pressure.
\end{abstract}

Keywords: green infrastructure, greenways network, ecological structure and sustainable urbanization. 


\section{Introdução}

O processo de planeamento, ordenamento e gestão do território tem por base a proteção e integração dos elementos biofísicos, culturais, recreativos e paisagísticos. Todo o processo de planeamento ambiental deverá orientar as intervenções antrópicas no sentido de reconhecer, conservar e promover elementos naturais e culturais que, por terem características únicas, deverão ser sujeitos a um ordenamento e planeamento ambientalmente sustentáveis, contribuindo desta forma para a qualidade de vida dos habitantes (Ferreira 2010a).

Considerando os conceitos, definições e métodos utilizados para a sua definição, Infra-estrutura Verde (IV) é sinónimo de Estrutura Ecológica (EE) da Paisagem ou do Território. A Estrutura Ecológica um determinado território reconhece os sistemas ecológicos fundamentais com vista à implementação sustentável da estrutura edificada (Ferreira, $2010^{\mathrm{a}}$ e Machado, 2004). Em Portugal, para alem da legislação definir e obrigar a integração da EE nos Instrumentos de Gestão Territorial (IGT), a designação de infra-estruura Verde é pouco utilizada e difundida.

Por sua vez, os Corredores Verdes (CV) constituem uma componente importante da Infra-Estrutura Verde (Bennedict e McMahon,2006) e podem ser definidos com base na Estrutura Ecológica Territorial, consistindo num instrumento eficaz de requalificação ambiental de territórios degradados e ecologicamente sensíveis. Estas estruturas têm dado um contributo significativo na compatibilização das áreas ecologicamente sensíveis com o desenvolvimento e reestruturação do tecido urbano. Nesse sentido tem contribuído para a requalificar a malha urbana existente e promover um suporte para a regeneração ecológica (incluindo a recuperação do potencial de biodiversidade no espaço urbano).

Assim, neste artigo a Infra-Estrura Verde é sinónimo de Estrutura Ecológica (EE). Esta deverá constituir um instrumento de planeamento ambiental e de ordenamento do território que oriente a ocupação e transformação antrópica do território.

"O conceito estrutura ecológica prende-se com a proteção e integração dos elementos biofísicos, culturais, recreativos e paisagísticos do território convergindo 
para a idéia de sustentabilidade. Deverá orientar as intervenções antrópicas no sentido de reconhecer, conservar e promover elementos naturais e culturais que, por terem características únicas, deverão ser sujeitos a um ordenamento e planeamento ambientalmente sustentável, contribuindo desta forma para a qualidade de vida dos munícipes" (Ferreira et al, 2010b e Machado et al, 2004).

A Estrutura Ecológica pretende estabelecer o "Continuum Naturale" ou seja um sistema natural, contínuo, que permita o funcionamento e desenvolvimento dos ecossistemas promovendo assim a biodiversidade. Considerando o exposto, a Rede Ecológica Municipal/Urbana a adotar, tem por função essencial contribuir para a estabilidade física e sustentabilidade ecológica do município, constituída por sistemas espaciais com diferentes funções, recreio, produção e proteção.

Ou seja, em territórios sob forte pressão antrópica, a Estrutura Ecológica deverá ser entendida como mais uma infra-estrutura essencial ao equilíbrio do território, a par das redes de estradas, de abastecimento de água e de energia elétrica entre outros. (Ferreira et al, 2004 e Ferreira 2010b).

A infra-estrutura verde deverá ser o suporte dos ecossistemas autóctones e da paisagem, deverá ter funções de corredor ecológico ao providenciar habitats para fauna e flora, constituir um filtro de ar e água, funções sociais e culturais ao promover um equilíbrio estético e paisagístico, propiciando à população espaços livres de recreio, lazer e educação ambiental. Trata-se assim de uma infraestrutura promotora de biodiversidade em ambiente urbano e indutora de uma sustentabilidade territorial, essencial para preservar os recursos naturais que sustentam o ambiente e as sociedades humanas (Figura 1).

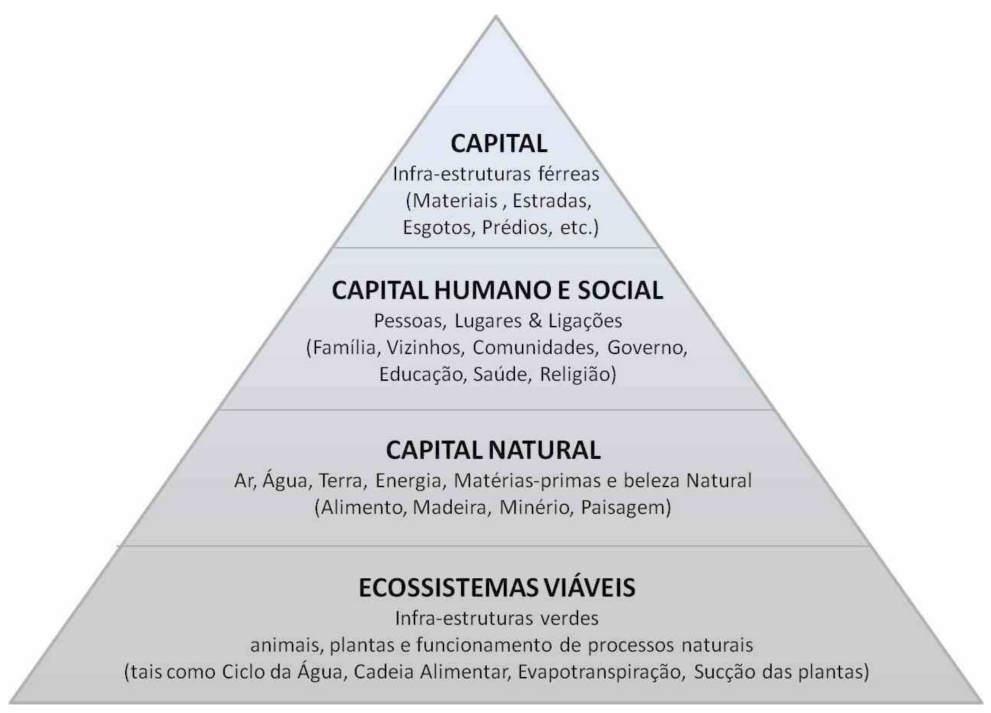

Figura 1 - Pirâmide da Sustentabilidade Territorial (Adaptado de Bennedict e McMahon, 2006).

Por último, para manter e potenciar esta infra-estrutura verde é essencial a 
introdução do conceito "condicionamento à edificabilidade" ou "aptidão para a edificação", que clarificara os critérios de aptidão dos solos, as funções urbanas e não urbanas. Deverá ainda incluir as áreas "non aedificandi" e as áreas com condicionantes à edificação, isto é, áreas do território sobre as quais assenta o funcionamento de determinados ecossistemas assim como outro tipo de áreas, nomeadamente, os espaços verdes, existentes e propostos, e os espaços associados à estrutura cultural e histórica do local (Ferreira, 2010 e OA/CMS, 2009).

A Rede de Corredores Verdes (CV) deve ser desenhada tendo por base a EE e deverá abranger as áreas com elevado valor ecológico cultural e paisagístico. A rede de $\mathrm{CV}$, pretende não só, proteger os recursos existentes, como também, compatibilizá-los com a atividade humana, contribuindo para uma melhor qualidade da paisagem e de vida da população. Segundo Machado et al (2004) "Redes de Corredores Verdes são espaços livres lineares que ligam grandes áreas não lineares ou grandes manchas de espaços naturais. Estes conjuntos constituem sistemas de espaços, planeados, projetado e geridos para fins múltiplos, incluindo objetivo ecológicos, recreativos, culturais, estéticos e produtivos, compatíveis com o conceito de sustentabilidade".

Tendo por base esta definição, a rede de Corredores Verdes em ambiente urbano) teve por base os seguintes fundamentos:

- Constituir uma alternativa às atuais tendências de ordenamento;

- Compatibilizar os efeitos espaciais negativos da evolução económica e a necessidade da salvaguarda da qualidade ambiental;

- Fomentar a interligação das questões do planeamento ambiental e paisagístico nas intervenções em matéria de ordenamento do território e de ambiente.

Ou seja, tendo por base a Estrutura Ecológica a Rede de Corredores Verdes tem como objetivo fundamentais:

- A delimitação de áreas com elevado valor ecológico cultural e paisagístico;

- A definição de uma rede de corredores verdes com ramificações no tecido urbano;

- A proteção dos recursos e a sua compatibilização com a atividade humana;

- Contribuir para uma melhor qualidade da paisagem e de vida da população.

Trata-se de uma filosofia de múltiplos objetivo: proteção de recursos, recreio e lazer, estabilidade ecológica, requalificação do remanescente da paisagem cultural e agrícola e proteção do património natural e construído.

Assim, de acordo com Ferreira et al (2004) e Jogman (2004) o "Corredor Verde constitui um sistema contínuo, estabelecendo ligações entre áreas de elevada concentração de recursos ecológicos, paisagísticos e culturais, promovendo a sua proteção e compatibilização com a atividade humana". O conceito de corredor verde introduz na Estrutura Ecológica a noção de "polivalência" dos espaços, ou 
seja a compatibilização entre espaços de proteção, produção e recreio. Para Machado et al (2004) e Ferreira et al (2010a) as redes de corredores verdes apresentam duas funções prioritárias, a ecológica e a social, a que se veio juntar recentemente a função económica. O conceito sugere uma enorme variedade de tipos e uma grande multiplicidade de usos, tornando-se difícil estabelecer uma definição única e consensual. Contudo, o "espaço aberto linear" representa a base comum de qualquer corredor verde, podendo este apresentar-se vocacionado para o recreio ou a conservação.

Em resumo, no âmbito dos processos de planeamento ambiental em meio urbano poderemos de uma forma simples entender a Estrutura Ecológica como uma Infraestrutura Verde essencial para os Instrumentos de Ordenamento e Gestão do Território e (incluindo os Planos de Urbanização), enquanto que a rede de Corredores Verdes, deve ser entendida como uma componente desenhada da infra-estrutura verde, que integra o modelo de ordenamento.

\subsection{Funções principais de uma rede de Corredores Verdes integrada na Infra-estrutura Verde.}

As Redes de Corredores Verdes (RCV) em ambiente urbano deverão permitir a integração de áreas de maior valor ecológico numa estrutura desenhada e organizada, criando novas componentes e potenciando ligações através dos subsistemas territoriais fundamentais que funcionam como infra-estruturas:

- Infra-estrutura azul (circulação da água);

- Infra-estrutura "verde" (produção de biomassa);

- Infra-estrutura cultural (paisagem e elementos culturais);

- Infra-estrutura de mobilidade sustentável (não motorizada).

A RCV deverá ser desenhada de forma a desempenhar as seguintes funções territoriais:

- Funções ecológicas:

a) Manutenção da biodiversidade: proteção de áreas naturais, constituindo habitats.

b) Estabelecimento de ligações entre áreas de habitats e, consequentemente, o movimento de espécies, materiais e energia

c) Filtro natural à poluição das águas e poluição atmosférica. Purificação do ar através da libertação de oxigénio e "sumidouro" de $\mathrm{CO}^{2}$.

d) A fixação de poeiras, a proteção dos ventos e a regularização de brisas;

e) A regularização de amplitudes térmicas e da luminosidade atmosférica. Em ambiente urbano é particularmente eficaz em baixar a temperatura da água e do ar devido ao efeito sombra, devido à elevada evapotranspiração, e interfere 
positivamente nos processos hidrológicos, reduzindo os riscos de erosão.

f) A circulação da água pluvial a céu aberto e infiltração, promovendo a utilização da água local e torrencial.

- Funções sociais:

a) Fornecem espaços para recreio ativo e lazer;

b) A contribuição para o abastecimento alimentar em produtos frescos (hortas urbanas);

c) Melhoria da qualidade do ar;

d) Melhoria do conforto térmico;

e) Permitem a preservação do património histórico e cultural;

f) Ajudam a manter e valorizar a qualidade estética da paisagem;

g) Controle de fatores de risco

\section{Metodologia para a Delimitação de uma Infra -Estrutura Verde (Estrutura e Ecológica) e desenho de uma Rede de Corredores Verdes.}

O desenvolvimento da metodologia com vista à elaboração de uma Infra-estrutura Verde, teve por base as metodologias desenvolvidas para a delimitação de Corredores Verdes e de Estruturas Ecológicas de âmbito local como instrumentos de ordenamento e planeamento territorial. Estas constituem um processo inovador no quadro português (apesar da delimitação da estrutura ecológica ser obrigatória a partir de 1999) e neste artigo resume-se às metodologias utilizada em vários trabalhos em que o Departamento de Ciências e Engenharia do Ambiente (FCT/UNL) esteve envolvido com destaque para o Plano Municipal de Ambiente do Município do Barreiro, Estrutura Ecológica do Município de Alcobaça e Estrutura Ecológica e Rede de Corredores Verdes para o Município de Setúbal (em curso).

A Estrutura Ecológica (EE) deve constituir-se como um modelo de ocupação do território. A definição da $\mathrm{EE}$ deve ter por base o reconhecimento dos sistemas ecológicos fundamentais (rede hidrográfica, zona ribeirinha, áreas com risco de erosão, solos de elevado valor ecológico, vegetação espontânea, área de elevada concentração patrimonial), criando um sistema ecológico territorial onde a estrutura edificada (infra-estruturas viárias, habitação, equipamentos, indústria) seja implementada de forma racional, obedecendo a regras de localização que tenham em conta os valores ecológicos, de forma a promover a biodiversidade e 0 
uso sustentável do território (Ferreira, 2010 e Jongman e Pungetti, 2004). Só uma efectiva articulação entre as ocorrências naturais e os elementos construídos, em que as estruturas permanentes da paisagem são consideradas sistemas fundamentais de suporte às comunidades humanas, podem contribuir para uma melhor gestão das pressões e interesses, por vezes antagónicos, sobre o território, contribuindo para a sustentabilidade local (Figura 2).

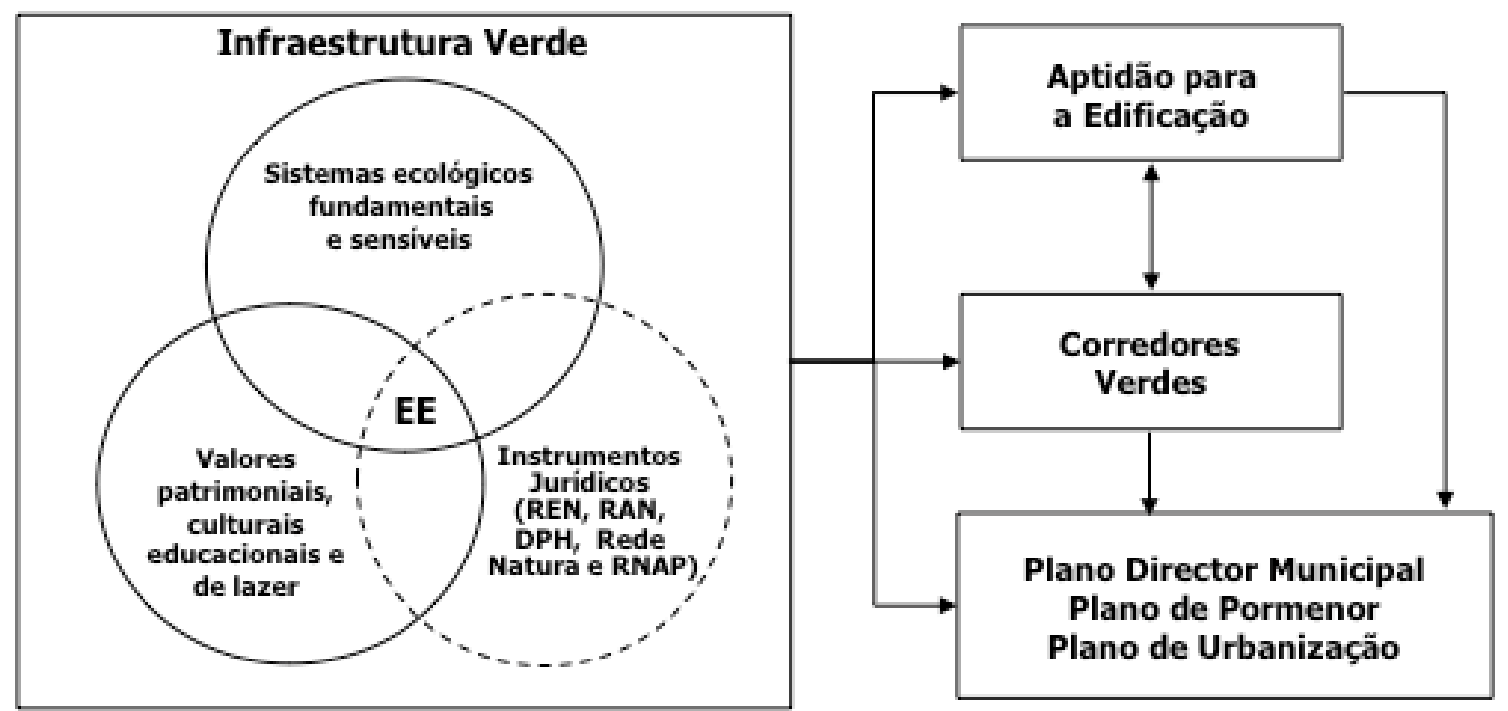

Figura 2 - Grandes vectores considerados na Estrutura Ecológica e principais resultados (Adaptado de Ferreira, 2010)

Assim, uma possível abordagem metodológica consiste em dividir a estrutura ecológica em duas: Estrutura Ecológica Principal (EEP) a uma escala local/municipal e Estrutura Ecológica Secundária (EES) à escala do plano de urbanização ou plano de pormenor.

A Estrutura Ecológica Principal (EEP) ou Fundamental integra as áreas que constituem o suporte dos sistemas ecológicos fundamentais e cuja protecção é indispensável ao funcionamento sustentável do território. Ou seja, são áreas localizadas nas situações ecológicas mais favoráveis à implantação da EEP. Engloba áreas de habitats prioritárias e ou importantes a nível local, ou seja, com maior interesse ecológico, imperativas no funcionamento dos sistemas naturais.

Este tipo de estrutura pretende assegurar a ligação da paisagem envolvente ao centro das principais zonas urbanas enquadrando as redes de circulação viária e pedonal e integrando os espaços que constituem os equipamentos colectivos "verdes" de maior dimensão e de concepção mais naturalista (Machado et al., 2004). 
Dever-se-á nesta estrutura privilegiar os sistemas contínuos de produção, protecção e recreio, incluindo, nomeadamente, a estrutura mais restritiva relativamente aos usos edificados, onde prevalece o carácter non aedificandi (Ferreira, 2010).

A Estrutura Ecológica Secundária (EES), é aqui entendida como uma estrutura ecológica urbana que visa fomentar e intensificar os processos ecológicos em áreas edificadas. Constitui assim uma estrutura de protecção, de regulação climática e de suporte da produção vegetal integrada no tecido edificado, integrando vazios urbanos, espaços públicos adjacentes às áreas mais urbanizadas, nomeadamente zonas residenciais, de serviços, de equipamentos de actividades económicas, áreas livres de protecção às infra-estruturas, logradouros, hortas urbanas, ente outros (Ferreira, 2010).

A utilização de um Sistema de Informação Geográfica é fundamental coma finalidade de poder lidar com uma base de dados complexa (figura 3). 


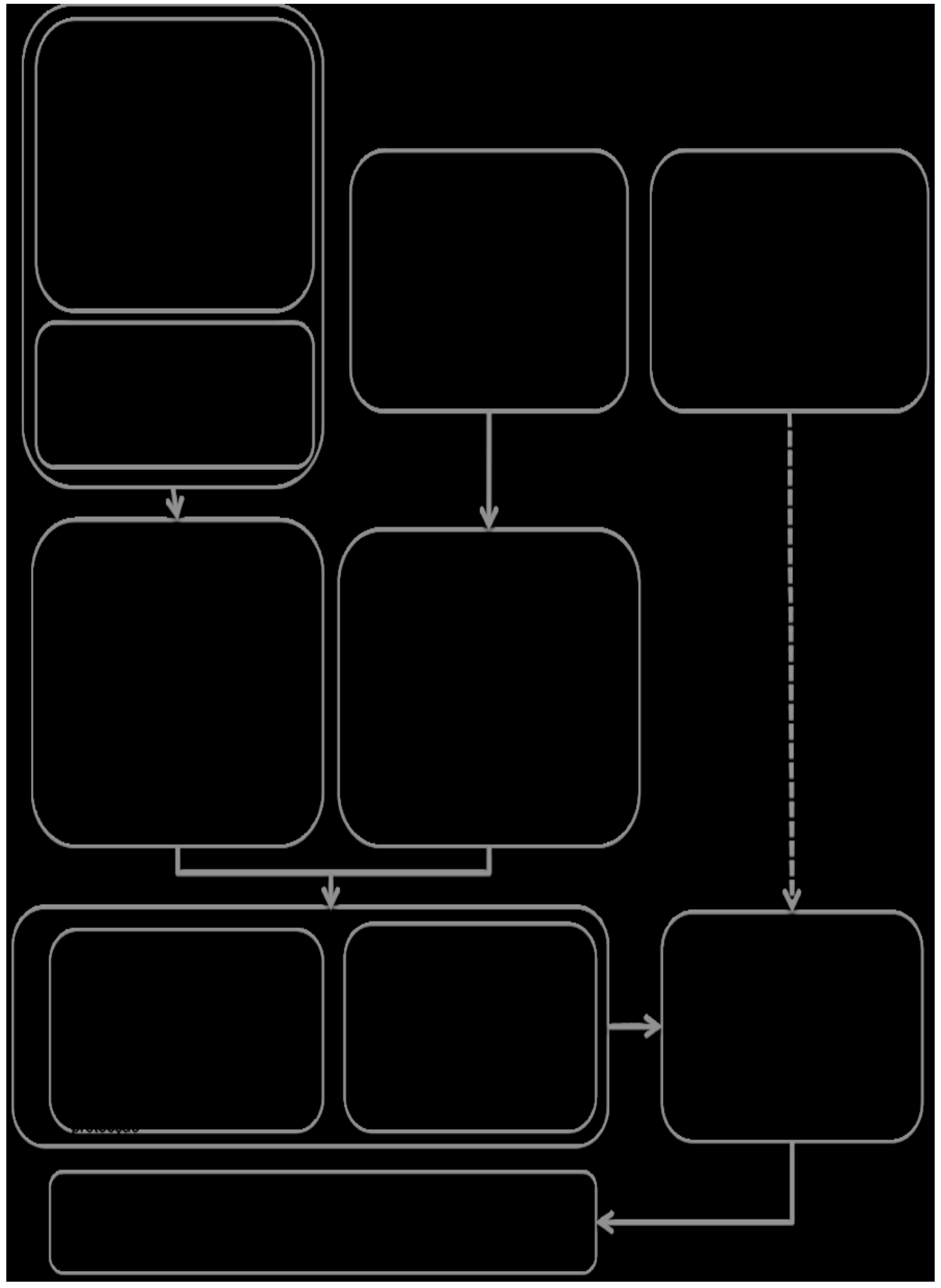

Figura 3 - Exemplo de um processo metodológico (Ferreira, 2010) 


\section{Infra-estrutura Verde Municipal: a Estrutura Ecológica e Rede de Corredores Verdes para do Município de Setúbal.}

O Município de Setúbal localiza-se na Área Metropolitana de Lisboa, na margem esquerda do Estuário do Rio Sado. Trata-se de um Município que possui um território de elevado valor ecológico abrangido por duas grandes áreas de projeção e conservação da natureza de âmbito nacional, a Reserva Natural do Estuário do Sado e o Parque Natural da Arrábida, mas ao mesmo tempo, possui uma grande área industrial (indústria de papel, estaleiros navais, produção de cimento, extração de pedra, entre outros) e um tecido urbano que necessita de ser regenerado.

A definição de uma Estrutura Ecológica Municipal de Setúbal (EEMS) tem como objetivo a promoção do desenvolvimento sustentável do território de Setúbal através da compatibilização dos usos urbanos e rurais, com a integração e valorização do património natural, cultural e paisagístico. Pretende ainda, requalificar e ou regenerar os espaços de elevado valor ambiental em articulação com os instrumentos de execução urbanística (OA/CMS, 2009).

Pretende-se, para tal salvaguardar:

a) As áreas ambientalmente vulneráveis e de risco associadas a fenómenos de origem natural e/ou antrópica, através de mecanismos de avaliação que tenham em conta a dinâmica dos processos naturais (ex: cheias/inundações, deslizamentos, erosão, derrame de poluentes, poluição atmosférica, entre outros);

b) A paisagem tradicional através da proteção do sistema de quintas, recorrendo a mecanismos de regulamentação do uso e ocupação do solo, de modo a assegurar a sua recuperação e valorização para outros fins para além do residencial e agrícola, nomeadamente para alojamento temporário e atividades de lazer potenciadoras da sua localização natural, como equipamentos para idosos, crianças, ecoturismo, spa, entre outros;

c) O restante património cultural como complemento à estrutura ecológica propriamente dita;

d) A zona costeira (oceânica e estuarina) através de ações de compatibilização de atividades de lazer, recreio, pesca, portuárias e industriais com a defesa dos recursos e valores naturais;

e) As linhas de água principais, promovendo a sua requalificação e regeneração, em especial nas áreas urbanas por forma a constituir um elemento valorizador do espaço urbano;

f) O sobreiro (Quercus suber e Quercus faginea) preservando a cintura verde que envolvente o perímetro urbano de Setúbal, fortalecendo o seu papel na 
estrutura ecológica, nomeadamente reforçando a componente produção, lazer e recreio, por exemplo com a criação de um parque urbano.

g) As zonas pedonais (zonas livres de automóveis), cicláveis, ruas multifuncionais e todas áreas com potencial para descarbonização do transporte, implementando meios de transporte não poluentes reforçando a componente não motorizada e não produtora de $\mathrm{CO}^{2}$.

A Estrutura Ecológica Municipal proposta no modelo de organização espacial do território permitirá a implementação da perspectiva de desenvolvimento sustentável subjacente nos eixos de desenvolvimento estratégico. Para além salvaguardar os sistemas ecológicos existentes, permite criar novas unidades ecológicas que dêem continuidade à estrutura, quer através dos grandes corredores ecológicos intermunicipais, quer a um nível mais local, com a criação de áreas verdes de proteção e enquadramento, como é o caso das cinturas verdes juntos às áreas industriais.

A Estrutura Ecológica Municipal de Setúbal (EEMS), encontra-se organizada em Estrutura Ecológica Fundamental, correspondendo às componentes naturais e com "conectividade fundamental" e em Estrutura Ecológica Complementar, correspondendo a componentes "artificiais", decorrentes da ação do homem e com uma "conectividade complementar", distinguindo-se assim, de acordo com uma maior ou menor dependência da ação humana. A EEMS, enquanto instrumento de salvaguarda do sistema ecológico, pode-se decompor em subsistemas que refletem a sua correlação funcional. Estes subsistemas agregam diversas componentes, passiveis de representação por áreas, pontos ou corredores, de acordo com a sua maior ou menor conectividade. As áreas correspondem à unidades identificados em cada um dos subsistemas (ex. Solos, manchas de vegetação, entre outras), os pontos aos elementos patrimoniais classificados e os corredores asseguram a sua conectividade. Em solo urbano, a identificação dos corredores assume maior relevância pelas pressões e descontinuidades provocadas pelo processo urbanístico. Assim, na lógica das funções principais, o sistema ecológico é assegurado através de quatro subsistemas com correspondentes funções, em que os dois primeiros têm funções essencialmente ecológicas e os dois últimos, funções ecológicas derivadas da ação humana (figura4). 


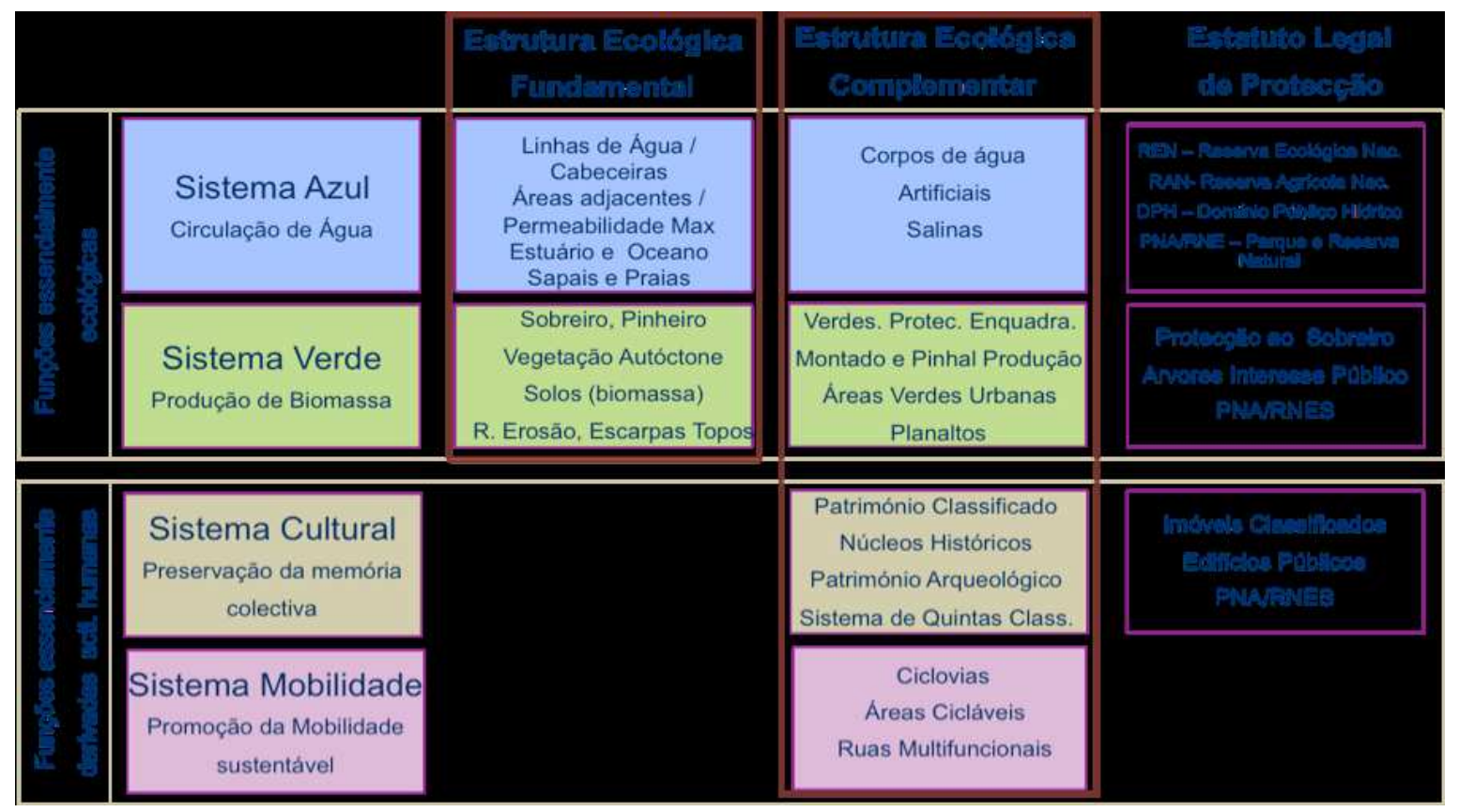

Figura 4 - Subsistemas da Estrutura Ecológica do Município de Setúbal (Adaptado de OA/CMS, 2009)

A Estrutura Ecológica Fundamental (Figura 4 e Figura 5), dentro do subsistema azul integra as linhas de água, áreas adjacentes e cabeceiras, áreas de permeabilidade máxima, estuário e oceano incluindo áreas adjacentes, sapais e praias e dentro do subsistema verde integra as áreas de sobreiros, as áreas de pinheiros, a vegetação autóctone, os solos de elevada capacidade de produção de biomassa, as escarpas, vertentes e risco de erosão e os topos.

A Estrutura Ecológica Complementar dentro do subsistema azul integra os corpos de água artificiais e as salinas. O subsistema verde integra os verdes de proteção e enquadramento, os montados, as áreas de produção de pinheiro, as áreas verdes em solo urbano e os planaltos. Dentro do subsistema cultural integra o sistema de quintas classificadas e paisagem associada, os núcleos históricos e património classificado e património arqueológico. O subsistema mobilidade integra áreas cicláveis e ciclovias e ruas multifuncionais. A relação entre os vários subsistemas e a articulação das estruturas (fundamental e complementar) estabelece-se através de um sistema de corredores que implementa e concretiza esta estrutura, aproveitando as componentes existentes, criando novas componentes e potenciando ligações sobretudo através dos subsistemas culturais e de mobilidade, por exemplo, respectivamente, através das quintas e da rede de mobilidade suave.

A estrutura ecológica, enquanto instrumento tem um caráter regulador, visando a proteção dos sistemas, um caráter propositivo, visando a reposição de sistemas, e 
ainda, um caráter integrador, integrando-se nos diferentes âmbitos dos Instrumentos de Gestão Territorial e a várias escalas.

Com base da EE desenvolvida desenhou-se uma rede municipal de corredores verdes considerando três sistemas básicos da matriz constituinte da paisagem:

- Sistema de Linhas (constituído pelos elementos lineares da paisagem como linhas de água; linhas de festo; entre outros.);

- Sistema de Pontos (constituído pelos elementos pontuais da paisagem. Elementos marcantes do ponto de vista paisagístico e cultural, como por exemplo o património construído; o ponto cénico único; árvores notáveis; entre outros.);

- Sistema de Áreas (constituído por elementos mancha que delimitam áreas de importância ecológica ou concentração / manchas de elementos urbanos e culturais, como por exemplo matas; sobreirais; montados; pinhais; núcleos históricos; sapais; entre outros.).

As áreas consideradas definem uma rede de corredores exequível que proporcionam um uso e ocupação sustentável do uso do solo. Assim, para além das funções estritamente ecológicas a rede de Corredores Verdes de Setúbal (CVS) é essencialmente constituída por corredores vocacionados para proporcionar às populações áreas de recreio e lazer, áreas livres, áreas de acesso a espaços "naturais" e "culturais" (Figura 5) 


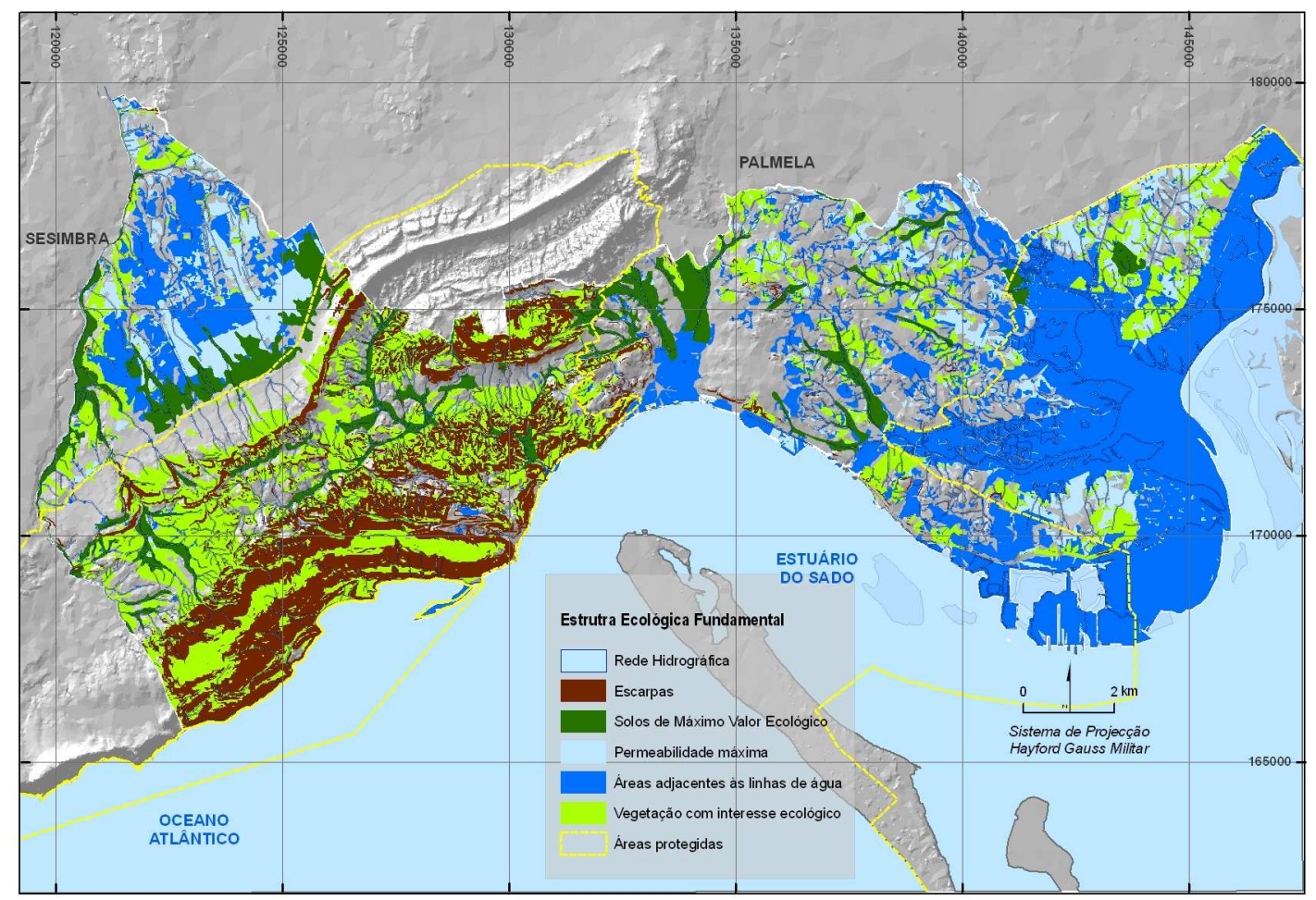

Figura 5 - Estrutura Ecológica Fundamental de Setúbal (OA/CMS, 2009) 


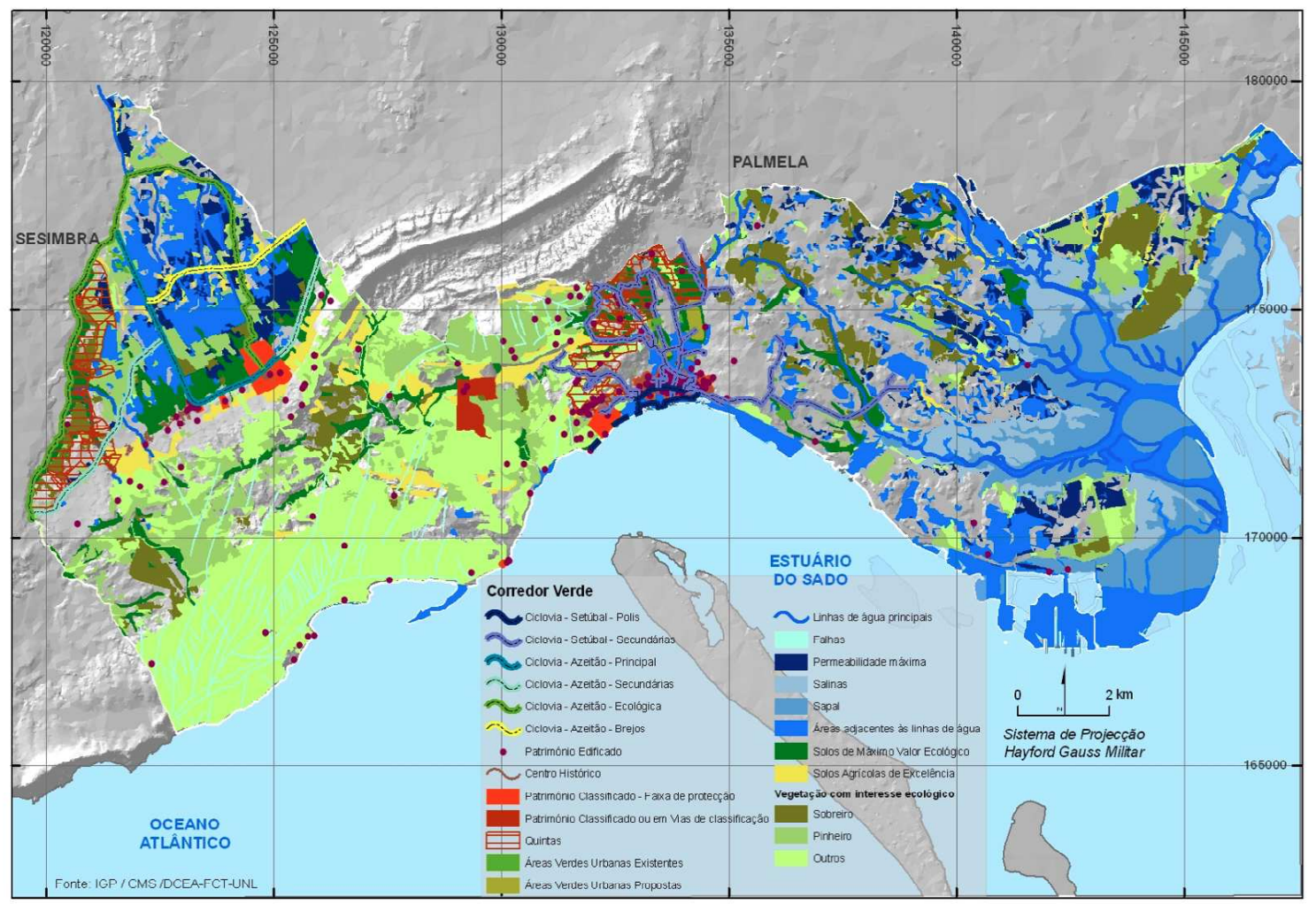

Figura 6 - Base para a delimitação da Rede de Corred. Verdes (OA/CMS, 2009)

No âmbito da "mobilidade" no interior do corredor verde, as "áreas cicláveis" de Setúbal (plano de intenções a nível de estudo prévio) surgem como estradas "verdes" que permitem o usufruto do corredor verde. Tomando como exemplo um "corredor recreativo", a concretização da rota poderá ser efetuada com recurso a ciclovias, caminhos pedonais entre outras formas de mobilidade não motorizada.

Nesta rede incluíram-se igualmente todos os espaços verdes urbanos existentes e programados.

A Rede de Corredores Verdes Municipal, organiza-se em 3 tipos de corredores: Corredor Ecológico, Corredor Produção e o Corredor Lazer, Recreio e Património

4. Infra-estrutura Verde à escala urbana: Corredor Verde Monsanto - Av. da Liberdade em Lisboa. 
O Corredor Verde de Monsanto à Avenida da Liberdade recentemente inaugurado é uma das componentes da Infra-estrutura Verde de Lisboa, ou seja, da Estrutura Ecológica Fundamental que compõe o Plano Verde da Capital da autoria do Professor Doutor Ribeiro Telles (Telles, 2001).

O Corredor com a extensão de $6,5 \mathrm{~km}$, faz a ligação entre a Praça dos Restauradores (inicio do eixo arborizado da Avenida da Liberdade na Baixa da cidade) e o Parque Florestal de Monsanto (900 ha) para pedestres e bicicletas, por meio de um corredor contínuo que vai fazendo a ligação a diferentes espaços verdes.

Permite assim a ligação entre as áreas urbanas densamente densificadas do centro e o pulmão verde da Cidade (Figura 7).

Este projecto agora concretizado é um exemplo, de como um simples corredor verde pode fazer a ligação entre vários elementos (áreas e pontos), como por exemplo, jardins, parques, logradouros, áreas florestais urbanas e áreas de elevada concentração de valores patrimoniais.

Este corredor verde está especialmente vocacionado para o recreio e lazer, contribuindo de uma forma clara para a melhoria da qualidade de vida da população lisboeta ao mesmo tempo que proporciona novos produtos turísticos.

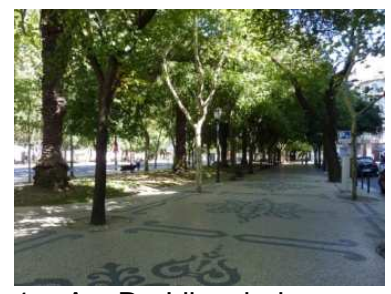

1 - Av. Da Liberdade

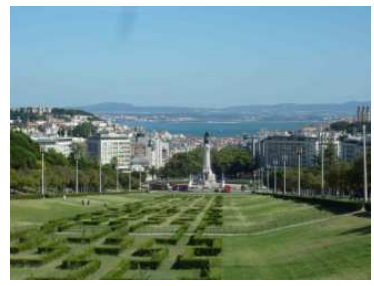

2- Prq. Eduardo VII

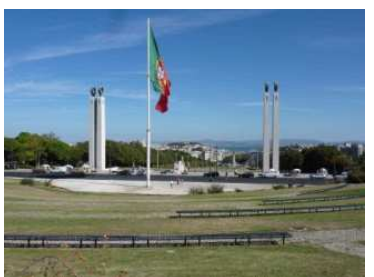

3- Jardim Amália Rodrigues

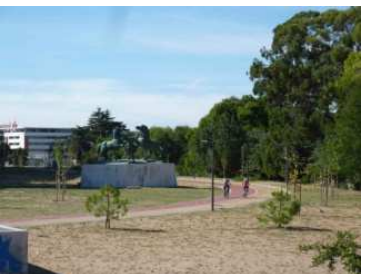

4 - Jardim Palácio da Justiça

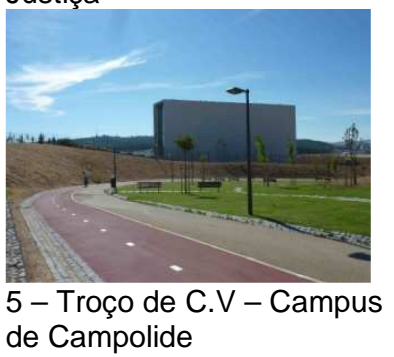




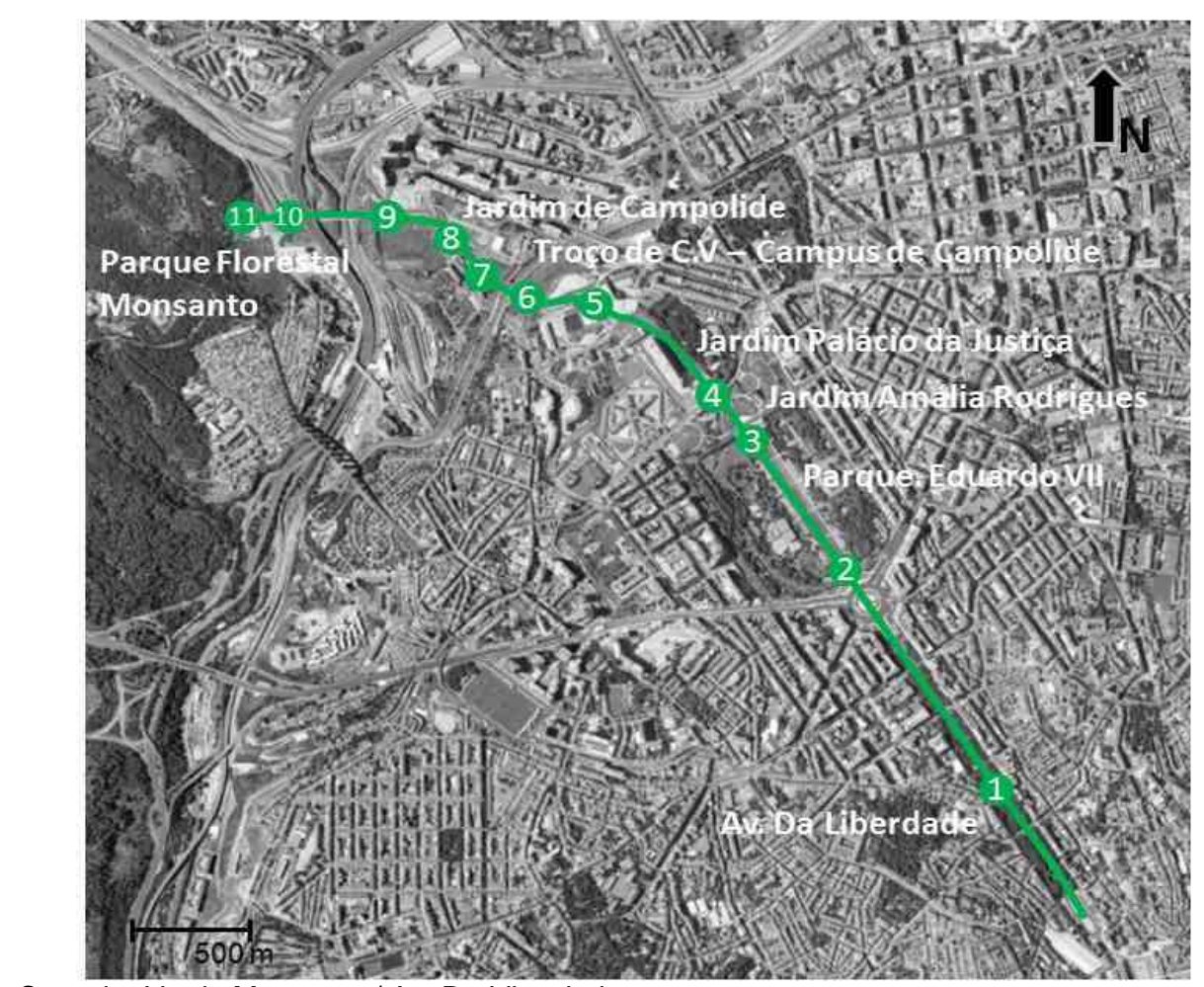

Corredor Verde Monsanto / Av. Da Liberdade

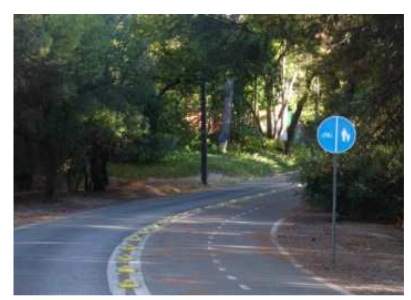

11 - Parque Florestal de Monsanto

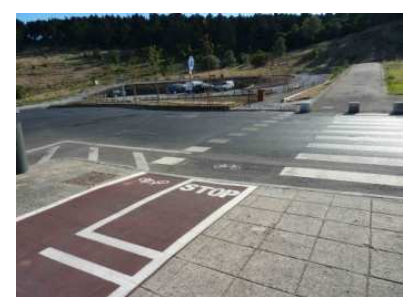

10 - Parque Florestal de Monsanto

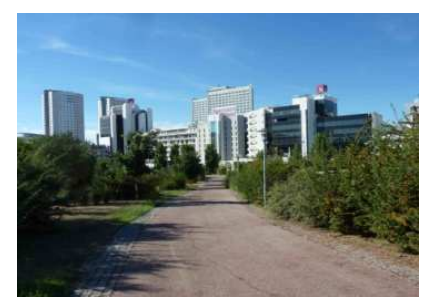

9 - Jardim de Campolide

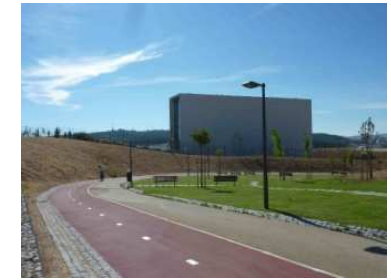

5 - Troço de C.V - Campus de Campolide

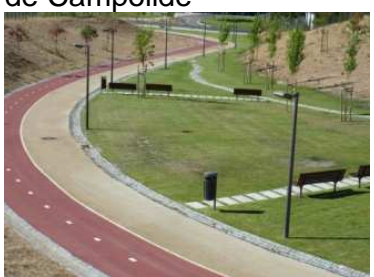

6 - Troço de C.V - Campus de Campolide

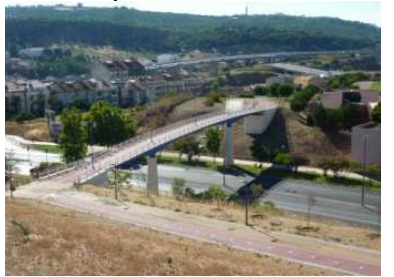

7 -Passagem

pedonal/ciclável

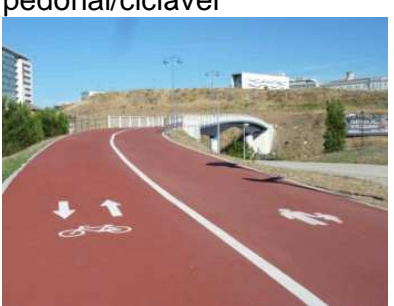

8 - Passagem pedonal /ciclável

Figura 7 - Corredor Verde entre o Parque Florestal de Monsanto e a Avenida da Liberdade. (Fotografia aérea: Google Maps. Fotografias efetuadas em Agosto de 2010)

\section{Remate}

Ao longo deste artigo constamos a importância que as Infra-estruturas verdes assumem no desenvolvimento sustentável das cidades a várias escalas.

Com o objectivo de garantir a protecção das funções ecológicas vitais do território e da cidade, dependentes do grau de conectividade da Infra-estrutura Verde Municipal desenhada, torna-se essencial garantir a existência de uma Estrutura 
Ecológica Urbana (EEU) a ser desenvolvida nos Planos de Pormenor e Planos de Urbanização.

A Estrutura Ecológica Urbana, tem como principal objectivo proporcionar, defender e promover os recursos ecológicos vitais para a sustentabilidade do espaço urbano. Deve viabilizar a coexistência de áreas de elevada concentração de valores ecológicos com o espaço urbano, viabilizar a defesa do capital natural do espaço urbano (água, ar, componente biótica) e humanizar e "embelezar" o espaço urbano, ou seja, viabilizar o capital humano e social (Ferreira 2010).

Neste contexto e com o objectivo de uma efectiva protecção da infra-estrutura verde, propõe-se que a Estrutura Ecológica Urbana seja desenvolvida e integrada nos Planos de Pormenor e Planos de Urbanização, de acordo com as orientações das infra-estruturas verdes desenvolvidas à escala municipal e regional. Assim, garante-se a concretização efectiva da proteção em espaço urbano dos corredores e áreas, necessários para a manutenção das funções ecológicas do território.

A Estrutura Ecológica Urbana (EEU), para além de assegurar um conjunto de funções ecológicas em meio urbano, assegura igualmente funções de recreio e lazer.

A EEU de Setúbal é constituída por (Ferreira 2010 e OA/CMS 2009):

a) Áreas com um uso predominantemente público (zonas verdes, parques e jardins urbanos públicos, verdes de protecção visual, poeiras e sonora; praças e alamedas de elevada concentração de património e acuidade visual; zonas desportivas, especialmente aquelas onde predomine o coberto vegetal; hortas urbanas /agricultura urbana parcelas agricultadas de pequena dimensão para usufruto da população urbana);

b) Áreas privadas e de acesso restrito: logradouros privados; jardins privados classificados / matas, casas senhoriais/palacetes; áreas de moradias com lotes profundos (agricultura e ou matas) abrangidos; por perímetro urbano; quintas e todo o sistema de paisagem associado, abrangidas por perímetro urbano.

A título de exemplo, apresenta-se de uma forma sumária (não exaustiva) os usos e acções compatíveis com a EE de Setúbal com incidência directa nos usos do solo. A tabela 1 apresenta um excerto das indicações fundamentais para os Planos de Pormenor e os Planos de Urbanização no sentido de promover o contínuo ecológico reduzindo os riscos de perda de conectividade da estrutura. 
Tabela 1. Usos e Acções Compatíveis com a Função Ecológica: Leitos e Margens dos Cursos de Água, Permeabilidade Máxima e Falhas Geológicas e Solos de Elevado Valor Ecológico

\begin{tabular}{|c|c|c|}
\hline \multicolumn{3}{|c|}{$\begin{array}{c}\text { Usos e Acções Compatíveis com a Função Ecológica dos } \\
\text { Leitos e Margens dos Cursos de Água, Permeabilidade Máxima e Falhas Geológicas e Solos de } \\
\text { Elevado Valor Ecológico }\end{array}$} \\
\hline $\begin{array}{l}\text { Componente } \\
\text { s Principais } \\
\text { da } \\
\text { EE } \\
\text { Fundamental }\end{array}$ & $\begin{array}{l}\text { Função Ecológica Principal } \\
\text { do município de Setúbal }\end{array}$ & $\begin{array}{l}\text { Usos e Acções Compatíveis com } \\
\text { Incidência Directa no Uso do Solo }\end{array}$ \\
\hline $\begin{array}{l}\text { Leitos e } \\
\text { margens } \\
\text { dos cursos } \\
\text { de água }\end{array}$ & $\begin{array}{l}\text { Ciclo hidrológico: } \\
\text { - regulação do ciclo da água } \\
\text { Biodiversidade: } \\
\text { - conservação de habitats (flora e fauna) } \\
\text { - refúgio de espécies } \\
\text { - regulação do ciclo de nutrientes } \\
\text { Prevencão de riscos naturais / socioeconómicos: } \\
\text { - redução da erosão fluvial através da galeria ripícola } \\
\text { - redução e prevenção dos riscos de cheia } \\
\text { - elevado valor cénico (vegetação ripicola e planos de } \\
\text { água) }\end{array}$ & $\begin{array}{l}\text { - galeria ripícola } \\
\text { - prados naturais } \\
\text { - agricultura de regadio } \\
\text { - espaços verdes de recreio e lazer } \\
\text { (compatíveis com a sensibilidade ambiental } \\
\text { dos habitats presentes) } \\
\text { - não edificáveis }\end{array}$ \\
\hline $\begin{array}{l}\text { Permeabilid } \\
\text { ade máxima } \\
\text { e falhas } \\
\text { geológicas }\end{array}$ & $\begin{array}{l}\text { Biodiversidade: } \\
\text { - conservação dos ecossistemas aquáticos } \\
\text { Ciclo hidrológico: recarga aquífera. } \\
\text { Prevenção de riscos naturais / socioeconómicos: } \\
\text { - protecção da qualidade da água } \\
\text { - redução das áreas de risco de cheia e de inundação } \\
\text { - redução do risco de intrusão salina }\end{array}$ & $\begin{array}{l}\text { - matas e floresta } \\
\text { - prados naturais } \\
\text { - espaços verdes de recreio e lazer (que } \\
\text { promovam a permeabilidade e que não } \\
\text { constituam um risco à contaminação aquífera) } \\
\text { - não edificáveis }\end{array}$ \\
\hline $\begin{array}{l}\text { Solos de } \\
\text { elevado } \\
\text { valor } \\
\text { ecológico }\end{array}$ & $\begin{array}{l}\text { Biodiversidade: } \\
\text {-promoção da sustentação de comunidades vegetais } \\
\text { de elevada biomassa ou de comunidades vegetais } \\
\text { específicas } \\
\text { Ciclo hidrológico: } \\
\text { - promoção da infiltração } \\
\text { Prevenção de riscos naturais /aspectos } \\
\text { - recioeconómicos: } \\
\text { - áreasa compatón ríveis de cheia / inundação } \\
\text { ecológica/biológica } \\
\text { - áreas preferenciais para a produção dos produtos } \\
\text { autóctones/tradicionais (vinho, azeite, maçãs entre } \\
\text { outros) }\end{array}$ & $\begin{array}{l}\text { - agricultura (preferencialmente de sequeiro) } \\
\text { exemplo: vinhas, pomares, olivais. } \\
\text { - em áreas rurais com forte disseminação de } \\
\text { espaços urbanos poderão constituir } \\
\text { excelentes espaços abertos para a prática de } \\
\text { desporto e lazer (baixa infra-estruturação } \\
\text { compatível com a sensibilidade do recurso). } \\
\text { - zonas não edificáveis (exceptuando os } \\
\text { apoios agrícolas) }\end{array}$ \\
\hline
\end{tabular}

Através das acções propostas pretende-se garantir um uso do solo coerente com a Estrutura Ecológica Urbana a ser desenvolvida nos Planos de Pormenor e 
Urbanização. Ou seja, os referidos planos devem garantir a conectividade da Rede Municipal.

Nota: Parte dos resultados já forma apresentados pelo $1^{\circ}$ autor no Pluris $2010,4^{\circ}$ Congresso Luso-Brasileiro para o Planeamento Urbano, Regional, Integrado, Sustentável, que decorreu em Faro (Portugal) sob o tema "Estrutura Ecológica e Corredores Verdes- estratégias territoriais para um futuro urbano sustentável".

\section{Referências Bibliográficas}

AEVV (2000) Guia de Buenas Práticas de Vías Verdes em Europa: ejemplos de realizaciones urbanas y periurbanas. Association Européenne des Voies Vertes, Namur.

Ahern, J. (2002) Greenways as Strategic Landscape Planning: theory and application. Wageningen University, Wageningen.

Benedict, M; McMahon, E (2006) Green Infrastructure. Linking Landscapes and Communities, Island Press, London.

Benton-Short, L; Short, J. (2008) Cities and Nature, Routledge, New York

DCEA/CMB (2009) Corredores Verdes e Estrutura Ecológica. Departamento de Ciências e Engenharia do Ambiente da FCT/UNL - Câmara Municipal do Barreiro. Monte da Caparica.

Erbil, A. (2007) Adapting Greenway Planning Strategy-Environmental Discourses in industrial and Developing Countries. VDM Verlgag Dr. Müller Publishers, Tennessee.

Fair, D. (2008) Sustainable Urbanism. Urban design with nature. John Willey \& Sons, New Jersey.

Ferreira, J. C. (2010)a, Estrutura Ecológica e Corredores Verdes - estratégias territoriais para um futuro urbano sustentável in Pluris 2010 - 4ํㅡㄴ Congresso LusoBrasileiro para o Planeamento Urbano, Regional, Integrado, Sustentável, Faro.

Ferreira, J. C. e Rocha, J. (2010)b, Rede de Corredores verdes para a Área Metropolitana de Lisboa: estratégias e oportunidades para a Requalificação Ambiental, in Corredores Verdes. Contributo para um Ordenamento Sustentável Regional e Local, Instituto Geográfico Português, Lisboa.

Ferreira, J. C.; Silva, C.; Tenedorio, J. A.; Pontes, S.; Encarnação, S and Marques, L. (2004) Coastal Greenways: Interdisciplinarity and Integration Challenges for the Management of Developed Coastal Areas. Journal of Coastal Research, SI 39, Itajaí, SC - Brazil, ISSN 0749-0208. 
Haines-Young, R.; Green, D.; Cousins, S. (1994) Landscape Ecology and GIS. Taylor \& Francis, London.

Jongman, R.; Pungetti, G. (2004) Introduction: ecological networks and greenways, in Ecological networks and greenways - Concept, designs, Implementation, Jongman \&Pungetti Eds., Cambridge University Press, Cambridge, pp. 1-6

Jongman, R. (2004) The context and concept on ecological networks, in Ecological networks and greenways - Concept, designs, Implementation, Jongman \&Pungetti Eds., Cambridge University Press, Cambridge, pp. 7-33.

Machado, J. et al (2004) A Estrutura Ecológica do Município de Alcobaça. Relatório Técnico Preliminar, Departamento de Ciências e Engenharia do Ambiente da FCT/UNL, Monte de Caparica.

OA/CMS. (2009) Estrutura Ecológica Municipal e Rede de Corredores Verdes. Oficina de Arquitectura / Câmara Municipal de Setúbal. Lisboa.

Williamson, S. K. (2003) Growing with Green Infrastructure, Heritage Conservancy, Doylestown.

Telles, R. (2001) Plano Verde - Estruturas Ecológicas e Componentes Ambientais, in Boletim Electrónico "Lisboa Urbanismo" № 15, acedido em Agosto de 2010: http://ulisses.cm-lisboa.pt 